\title{
PROPOSTA SIMPLIFICADA DE CODIFICACIÓ ALFANUMĖRICA EN ELS DOCUMENTS DE PLANEJAMENT URBANÍSTIC
}

\author{
Zamora-Mestre, Joan-Lluís i Fernàndez Rodríguez, José ${ }^{1}$ \\ Departament de Construccions Arquitectòniques I \\ Universitat Politècnica de Catalunya (UPC)
}

Remisión Artículo: 5-6-2007

Remisión definitiva: 25-9-2007

Palabras Clave: Planejament Urbanístic

Resumen: El planejament urbanístic ja ha adquirit plena maduresa i normalitat a l'estat Espanyol, tant pels tècnics redactors, com pels administradors públics, com pels ciutadans, i especialment per als professionals que són agents actius en els processos constructius de les ciutats i el territori.

Dins d'aquest procés de normalitat i continuïtat en la planificació del entorn humanitzat s'han formulat propostes tendents a unificar els procediments de treball, a establir índexs tipus de documentació i sobretot unificar les unitats de mesura que valoren els paràmetres quantitatius propis del planejament urbanístic. Aquest article vol ser una aportació més en aquesta línia de normalització i millora contínua d'aquests processos, mitjançant la formulació d'una proposta de codificació alfanumèrica simplificada en els documents de planejament urbanístic, desenvolupada i contrastada a partir d'un cas real.

\section{ANTECEDENTS}

L'any 2000 un equip de la ETSAV (UPC) va iniciar les tasques que han de conduir a la revisió del planejament urbanístic vigent en un municipi de prop de 10.000 habitants, situat a l'entorn de l'àrea metropolitana de Barcelona a cavall entre la mar mediterrània i un espai natural protegit.

A part dels problemes específics del planejament urbanístic d'aquest municipi es va detectar immediatament l'existència d'un problema de fons d'índole documental que dificultava no tan sols la comunicació entre les diferents persones de l'equip redactor sinó també la interrelació entre els diferents documents que formen un planejament urbanístic. En aquests moments un document oficial de planejament es desenvolupa intensament en quatre potes: la informació gràfica (plànols d'informació, de classificació i d'ordenació), la memòria (justificativa i descriptiva), la normativa (urbanística i d'edificació) i els annexes que venen a especificar més en detall alguns aspectes monogràfics (impacte ambiental, mobilitat generada, catàleg de patrimoni, etc).

Per tal que aquests quatre principals subdocuments del planejament urbanístic interactuïn correctament i coherent entre ells es fa imprescindible denominar les categories en ells

\footnotetext{
${ }^{1}$ Persona de contacto Joan Lluís Zamora, correo:joan.Iluis.zamora@upc.edu
} 
contingudes amb la mateixa codificació alfanumèrica. A més aquesta codificació no potser aleatòria sinó que, com succeeix sempre en el mon de la comunicació visual, ha de venir a reforçar la interpretació correcta del seu significat precís. Per tot plegat l'equip de treball de la UPC va considerar oportú desviar part del recursos disponibles per a desenvolupar l'encàrrec pròpiament dit i fer una petita recerca monogràfica prèvia a l'entorn d'aquest tema de la codificació. Finalment es va formular una proposta de codificació simplificada, la qual es va aplicar en fase de rodatge al planejament la redacció del qual es tenia encarregada i que és la que en aquest article es presenta.

\section{ACTUALITAT DEL PROBLEMA}

Els diferents agents urbanístics que cada dia consulten els planejaments vigents que els afecten es troben habitualment davant de documents redactats en diferents èpoques, per diferents equips, elaborats sobre diferents territoris i aprovats en diferents entorns temporals legislatius. Per tal de fer possible un equilibri entre la necessària diversitat $i$ autonomia de les diverses figures del planejament i l'exigència de seguretat jurídica que formulen els ciutadans es fa necessària, cada cop més, la normalització del llenguatge que fan servir els propis instruments de planejament en el seu desenvolupament documental. Aquest article vol fixar l'interès només en un dels elements d'aquest llenguatge: els codis alfanumèrics que identifiquen les diverses classificacions i qualificacions zonals del sòl.

Segons l'ordenament actual, pràcticament totes les figures del planejament arriben en algun moment de la seva tramitació a la taula de l'aprovació per part de les comissions territorials d'urbanisme. Probablement per aquesta posició central que detenten aquestes comissions ja fa temps que varen ser les primeres en expressar les dificultats que per als seus membres ponents representava l'estudi i avaluació de documents de planejament no plenament coincidents en el seu llenguatge documental.

Actualment la difusió immediata del contingut documental de les figures de planejament mitjançant la xarxa internet és ja una realitat gràcies als suports digitals protegits i a la comoditat que suposa la tele-consulta. Aquesta facilitat ha provocat un augment extraordinari del nombre d'interaccions de consulta entre agents i documents, la qual cosa ha posat encara més palesa la necessitat d'establir unes regles "ortogràfiques" comunes que facilitin una còmoda navegació pels diversos documents i alhora una correcta interpretació per a qui ha d'accedir constantment a diferents planejaments municipals.

Per a que cadascuna d'aquestes consultes siguin vàlides i completes cal una interrelació constant entre la informació gràfica (plànols) i la informació alfanumèrica (memòria i normativa). A nivell operatiu significa que ha de ser possible relacionar informàticament diverses dades amb orígens diferents però que donen simultàniament informació d'un mateix indret del territori (informació georeferenciada o bases de dades associades).

Durant anys es va atorgar tàcitament una certa llibertat d'estil als equips redactors de planejament, la qual va tenir en el seu moment un efecte positiu perquè va incentivar la innovació. Però poc a poc els equips redactors han anat aprenent els uns dels altres i s'han anat encaminant cap a pràctiques d'edició i redacció similars. Aquesta diversitat inicial doncs 
ha passat ràpidament de ser un incentiu a ser un obstacle quan el que es vol és donar la màxima difusió a aquests documents o quan es volen fer estudis o anàlisis comparatius de més d'un municipi alhora, o quan es vol tenir una visió territorial més amplia que la municipal o traslladar experiències i propostes d'interès. Es planteja doncs la oportunitat de realitzar una certa poda i actualització dels diversos sistemes de codificació actualment a l'ús.

Hom es troba doncs davant una situació similar a la que va suposar en el seu dia la homogeneïtzació de las diverses bases cartogràfiques geogràfiques mundials. De fet el planejament urbanístic podria ser considerat com un graó més de la base cartogràfica compartida socialment, precisament el graó que incorpora aquells elements no tangibles del territori però que si tenen la vigència pròpia d'una llei.

Els Sistemes d'Informació Territorial amb suport informàtic, com els que administra un Cadastre o una Direcció General d'Urbanisme o una Diputació, requereixen també d'una codificació unificada en la seva base per tal de donar coherència documental i continuïtat territorial al propi sistema (sigui d'abast municipal, provincial, regional, etc.) i evitar al màxim que cada planejament sigui una illa tancada i excepcional respecte del immediat planejament veí.

A la taula següent es mostren alguns dels projectes vigents de difusió de la informació territorial que incorporen dades urbanístiques dins de l'àmbit de l'estat espanyol.

\begin{tabular}{|l|l|l|l|}
\hline $\begin{array}{l}\text { Projectes de difusió de la informació que incorporen documents de planejament } \\
\text { urbanístic }\end{array}$ \\
\hline $\begin{array}{l}\text { Projecte de } \\
\text { difusió }\end{array}$ & Àmbit territorial & Descripció & $\begin{array}{l}\text { Organisme } \\
\text { responsable }\end{array}$ \\
\hline SITMUN & $\begin{array}{l}\text { Municipal i } \\
\text { Europeu }\end{array}$ & $\begin{array}{l}\text { Sistema d'Informació } \\
\text { Territorial Municipal }\end{array}$ & Diputació de Barcelona \\
\hline SITPU & $\begin{array}{l}\text { Autonòmic - } \\
\text { Catalunya }\end{array}$ & $\begin{array}{l}\text { Sistema d'Informació } \\
\text { Territorial del Planejament } \\
\text { Urbanístic }\end{array}$ & $\begin{array}{l}\text { Direcció General } \\
\text { d'Urbanisme de la } \\
\text { Generalitat de Catalunya }\end{array}$ \\
\hline SIPUA & Autonòmic - & $\begin{array}{l}\text { Sistema d'Informació del } \\
\text { Planejament Urbanístic } \\
\text { d'Andalusia }\end{array}$ & $\begin{array}{l}\text { Direcció General } \\
\text { d'Ordenació del Territori i } \\
\text { Urbanisme de la Junta } \\
\text { d'Andalusia. }\end{array}$ \\
\hline INDALO & Estat espanyol & $\begin{array}{l}\text { Intercanvi de dades entre } \\
\text { administracions públiques }\end{array}$ & $\begin{array}{l}\text { Secretaria d'Estat per a } \\
\text { l'Administració Pública. }\end{array}$ \\
\hline
\end{tabular}

El Sistema d'Informació Territorial Municipal (SITMUN) és una eina de gestió que integra cartografia i bases de dades amb tecnologia servidor de mapes via web, que millora la quantitat i qualitat de la informació territorial municipal. Aquesta eina permet la visualització estructurada de cartografies temàtiques, com el cadastre, el planejament urbanístic, infraestructures, xarxes serveis, ortofotos, etc..., gestionades de forma centralitzada a la Diputació de Barcelona, posant aquesta informació a l'abast dels usuaris municipals (Extranet) i del ciutadà (Internet). Aquest projecte de difusió, a més forma part de la Xarxa Europa SITMUN. La informació relativa al planejament és només una transcripció del planejament de cada municipi. 
El Sistema d'Informació Territorial del Planejament Urbanístic (SITPU) és una eina de gestió específica per consultar planejament urbanístic. Aquesta eina permet visualitzar la classificació del sòl, els usos principals i la delimitació dels sectors de planejament derivat. La difusió d'aquesta informació és molt limitada, i els usuaris i l'explotació és bàsicament a càrrec de la Generalitat de Catalunya.

El Projecte d'Intercanvi de Dades (INDALO) té com a objectiu esdevenir el model de dades sobre el qual es recolzin totes les comunicacions entre les Administracions públiques de l'estat Espanyol. Es divideix en diversos dominis temàtics, com ara el de Territori, el qual està format per quatre subsistemes: Georeferenciació, Cartografia, Cadastre i Urbanisme.

Aquests projectes de difusió no aporten cap proposta de codificació urbanística pròpia, però el seu esforç per difondre alhora el planejament de molts municipis serveis per fer palesa la necessitat d'unificar les codificacions entre els diferents documents.

\section{REQUERIMENTS PER A UNA PROPOSTA DE RECODIFICACIÓ}

\section{Universalitat}

Si hom es planteja unificar i sistematitzar la codificació del planejament urbanístic s'ha de considerar que la proposta presentada sigui útil per a la majoria de les situacions però no pas pretendre que ho sigui per a la totalitat. La immensa majoria dels municipis són de petita 0 mitjana grandària i en canvi són molt pocs els grans municipis. Resulta més operatiu plantejar una codificació simplificada i útil per a la major part dels municipis i deixar que els grans municipis tinguin, si escau, una codificació específica, probablement desenvolupada a partir dels models simplificats.

\section{Manteniment}

La informació urbanística és cada dia més volàtil perquè els processos legals de modificació, actualització, adaptació i concreció del planejament són constants. Si inicialment els esforços institucionals es van centrar en la redacció d'un bon planejament i posteriorment en la seva adequada gestió, cada cop s'apunta més la necessitat d'adreçar esforços cap el manteniment al dia de la pròpia informació urbanística.

La elaboració d'un document de planejament refós ha passat de ser quelcom excepcional a ser una necessitat diària, imperiosa per al bon govern urbà i territorial. La informació urbanística necessita d'una contínua actualització per tal que les consultes formulades pels agents urbanístics puguin ser realment vàlides a tots els efectes. Aquesta tasca de contínua posada al dia dels documents del planejament podrà ser menys artesanal quan més definit i a la vegada més flexible sigui el sistema de codificació emprat.

No es pot oblidar tampoc el fet, demostrat pel dia a dia de l'experiència de la gestió urbanística, de la necessitat de disposar també d'un arxiu de planejaments històrics. Drets urbanístics concrets recollits per sentències han obligat a retrocedir actuacions i aplicar de nou entorns de planejament pretèrits. 


\section{Grafisme}

La normalització de la codificació també podria arribar a incloure aspectes de representació gràfica, com poden ser els tipus de línia emprats per delimitar els diferents àmbits (classificació del sòl, planejament derivat, zonificació, proteccions, etc.) o les games de colors per a cada un dels sistemes o subsistemes i de les zones o subzones si s'escau. Es tractaria en aquest cas d'una normalització encaminada a la unificació d'estils com si es pretengués evitar el reconeixement de la ma concreta de l'autor de cada planejament. Nosaltres no considerem que aquest sigui ara el tema prioritari i urgent a resoldre. Àdhuc considerem que aquesta interpretació tan restrictiva de la normalització generaria conflictes innecessaris entre els professionals redactors del planejament i els distanciaria de l'assoliment d'altres acords ara més interessants. Per tant, la normalització del grafisme no és el problema sobre el que es focalitza aquest article, el qual s'orienta cap a un problema més de fons de la identificació de la informació que no pas de la seva representació sensible.

\section{ESTAT ACTUAL}

Aquest problema que en aquestes línies es debat no és nou ni en la seva diagnosi ni original en el plantejament de possibles solucions. A llarg del treball d'elaboració d'aquest Pla General d'Ordenació Urbana es van detectar i analitzar altres aportacions anteriors.

A la taula següent es mostren alguns projectes de normalització dels codis d'identificació realitzats a l'Estat Espanyol. Aquests projectes han estat promoguts de forma gairebé exclusiva per aquells agents amb la necessitat de difondre documents de planejament urbanístic generats amb criteris diferents.

\begin{tabular}{|l|l|l|l|}
\hline \multicolumn{3}{|l|}{ Projectes de normalització de la informació urbanística } \\
\hline $\begin{array}{l}\text { Projecte de } \\
\text { normalització }\end{array}$ & Ámbit territorial & $\begin{array}{l}\text { Descripció del } \\
\text { document }\end{array}$ & $\begin{array}{l}\text { Organisme } \\
\text { responsable }\end{array}$ \\
\hline $\begin{array}{l}\text { Sistematització } \\
\text { dels Codis } \\
\text { d'Identificació del }\end{array}$ & $\begin{array}{l}\text { Autonòmic - } \\
\text { Catalunya }\end{array}$ & $\begin{array}{l}\text { Definició de criteris de } \\
\text { contingut documental, } \\
\text { representació gràfica i } \\
\text { codificació }\end{array}$ & $\begin{array}{l}\text { Direcció General } \\
\text { d'Urbanisme de la } \\
\text { Generalitat de } \\
\text { Catalunya }\end{array}$ \\
\hline ITPLAN & Autonòmic - & $\begin{array}{l}\text { Instrucció Tècnica } \\
\text { sobre normalització } \\
\text { dels instruments de } \\
\text { planejament urbanístic }\end{array}$ & $\begin{array}{l}\text { Conselleria de Foment } \\
\text { de la Junta de Castella } \\
\text { i Lleó }\end{array}$ \\
\hline
\end{tabular}

A aquests projectes institucionals de normalització, caldria afegir també les propostes de sistematització dels instruments normatius del planejament urbanístic i la seva aplicació en el treball municipal realitzades per part de Montserrat Hosta, Cap de l'Àrea de Serveis Territorials de l'Ajuntament de Vilassar de Mar.

Les tres aportacions coincideixen sobre la necessitat d'abordar aquest tema, però no són coincidents alhora de fer propostes al respecte. Per tal de facilitar una ràpida lectura comparativa s'adjunta un quadre resum. 


\begin{tabular}{|c|c|c|c|}
\hline Tema & $\begin{array}{l}\text { Generalitat de } \\
\text { Catalunya }\end{array}$ & $\begin{array}{l}\text { Montserrat Hosta i Privat, } \\
\text { arquitecta }\end{array}$ & $\begin{array}{l}\text { Junta de } \\
\text { Castilla y León }\end{array}$ \\
\hline $\begin{array}{l}\text { Classificació } \\
\text { del sòl } \\
\text { i } \\
\text { denominació de les } \\
\text { figures de } \\
\text { planejament derivat }\end{array}$ & $\begin{array}{l}\text { Codi format per un conjunt } \\
\text { de } 3 \text { lletres majúscules: } \\
\text { p.e.: SUC (sòl urbà } \\
\text { consolidat), SNU ( sòl no } \\
\text { urbanitzable) } \\
\text { p.e.: PMU (pla millora } \\
\text { urbana), PEP (pla especial } \\
\text { de protecció) }\end{array}$ & $\begin{array}{l}\text { Codi format per un conjunt de } 2 \\
\text { lletres majúscules, cara a } \\
\text { diferenciar el règim principal i a } \\
\text { continuació es complementa amb } \\
\text { lletres minúscules; excepte el sòl } \\
\text { no urbanitzable on es proposa un } \\
\text { codi de tres lletres majúscules. } \\
\text { p.e.: SUc (sòl urbà consolidat), } \\
\text { SnU (sòl no urbanitzable) } \\
\text { p.e.: PPr (pla parcial residencial) }\end{array}$ & $\begin{array}{l}\text { Codi format per un conjunt de } \\
2 \text { a } 4 \text { lletres majúscules: } \\
\text { p.e.: SU-C (sòl urbà consolidat, } \\
\text { SR (sòl rústec) } \\
\text { p.e.: PP (pla parcial), PE (pla } \\
\text { especial) }\end{array}$ \\
\hline $\begin{array}{l}\text { Sistemes i } \\
\text { subsistemes } \\
\text { urbanístics }\end{array}$ & $\begin{array}{l}\text { Codi principal format per un } \\
\text { conjunt de dos lletres } \\
\text { majúscules. Per a indicar } \\
\text { els subtipus o diferents } \\
\text { categories s'introdueix una } \\
\text { xifra en la tercera posició. } \\
\text { p.e.: VP1 (parcs) } \\
\text { p.e.: EQ3 (equipament } \\
\text { administratiu) }\end{array}$ & $\begin{array}{l}\text { Codi format per una lletra } \\
\text { majúscula per al sistema i una } \\
\text { lletra minúscula per al subtipus; } \\
\text { excepte l'habitatge dotacional. } \\
\text { p.e. Vj (jardins urbans), Ea } \\
\text { (equipament administratiu) } \\
\text { p.e.: HD (habitatge dotacional) }\end{array}$ & $\begin{array}{l}\text { Codi principal format per un } \\
\text { conjunt de dos lletres } \\
\text { majúscules. Per a indicar els } \\
\text { subtipus o les diferents } \\
\text { categories s'utilitza una tercera } \\
\text { lletra majúscula separada per } \\
\text { un guió. } \\
\text { p.e.: EL-P } \\
\text { (espai lliure-parc), } \\
\text { EQ-M (equipament } \\
\text { administratiu) }\end{array}$ \\
\hline Zonificació & $\begin{array}{l}\text { Codi principal format per un } \\
\text { sistema alfa numèric: les } \\
\text { dos primeres posicions } \\
\text { indiquen la zona, la tercera } \\
\text { posició, formada per una } \\
\text { lletra minúscula, indica la } \\
\text { subzona. } \\
\text { De l'1 al } 19 \text { - zones en sòl } \\
\text { urbà } \\
\text { Del } 20 \text { al } 27 \text { - zones en sòl } \\
\text { no urbanitzable } \\
\text { Del } 30 \text { al } 39 \text { - zones en sòl } \\
\text { urbanitzable (les subzones } \\
\text { indiquen densitats) } \\
\text { p.e.: } 2 \text { a, 30b }\end{array}$ & $\begin{array}{l}\text { Idèntica a la Generalitat de } \\
\text { Catalunya pel que fa al tipus de } \\
\text { codificació en sòl urbà però amb } \\
\text { diferents definicions: } \\
\text { De l'1 al } 13 \text { - zones en sòl urbà: } \\
\text { introdueix l'ús terciari i també les } \\
\text { zones "jòquer". } \\
\text { p.e.: } 8 \text { - zones ús terciari } \\
\text { p.e.: } 9 \text { - zones comodí } \\
\text { Pel que fa a les zones en sòl no } \\
\text { urbanitzable s'utilitzen només } \\
\text { lletres. } \\
\text { p.e.: foP (forestal protegit) }\end{array}$ & $\begin{array}{l}\text { Codi principal format per una } \\
\text { Iletra majúscula. } \\
\text { Per a indicar les diferents } \\
\text { subcategories s'utilitza una } \\
\text { segona lletra majúscula. } \\
\text { p.e.: RU (residencial } \\
\text { unifamiliar), IM (industrial } \\
\text { magatzem) }\end{array}$ \\
\hline
\end{tabular}




\section{BALANÇ DE LES PROPOSTES}

En general les tres propostes aquí analitzades presenten un elevat grau de maduresa i interessants aportacions, però cap d'elles arriba a resoldre de forma completa i simple el problema que aquí es planteja. Totes elles deixen temes pendents o be proposen solucions clarament simplificables. No n'hi ha prou amb la barreja de lletres majúscules, minúscules i xifres per a obtenir una combinatòria de codis que un ordinador pugui processar.

Cal estar atent també a les necessitats de la lectura visual i també fer un esforç per sistematitzar les categories urbanístiques.

La proposta que aquí és presenta és fruit d'un estudi i reflexió de les tres propostes comparades amb el interès de fer un pas més endavant que les integri i faciliti alhora la tasca del redactor i del lector en la major part dels casos. Tanmateix, com en qualsevol codificació, per als casos singulars sempre serà necessari plantejar solucions singulars.

\section{PROPOSTA SIMPLIFICADA}

Classificació del sòl: es proposar utilitzar com a codi principal 2 lletres majúscules per a cada tipus de sòl, seguides, si escau, de 2 lletres més minúscules per a indicar les subclassificacions.

\begin{tabular}{|c|c|c|c|}
\hline \multicolumn{4}{|c|}{ Classificació del sòl: règim } \\
\hline $\begin{array}{l}\text { NO URBANITZABLE } \\
(\mathrm{NU})\end{array}$ & $\begin{array}{l}\text { SÒL URBÀ } \\
\text { (SU) }\end{array}$ & $\begin{array}{l}\text { URBANITZABLE } \\
\text { (UR) }\end{array}$ & SISTEMES \\
\hline $\begin{array}{l}\text { Protegit } \\
\text { (NUp) } \\
\text { No protegit } \\
\text { (NUnp) }\end{array}$ & $\begin{array}{l}\text { Consolidat } \\
\text { (SUc) } \\
\text { No consolidat } \\
\text { (SUnc) }\end{array}$ & $\begin{array}{l}\text { Delimitat } \\
\text { (URd) } \\
\text { No delimitat } \\
\text { (URnd) } \\
\text { Amb planejament } \\
\text { aprovat } \\
\text { (URpa) }\end{array}$ & $\begin{array}{l}\text { Mobilitat } \\
\text { Espais lliures } \\
\text { Equipaments }\end{array}$ \\
\hline \multicolumn{3}{|l|}{ SÒL ÚS PRIVAT } & SÒL ÚS PÚBLIC \\
\hline
\end{tabular}

Àmbits de planejament: es proposa utilitzar com a codi principal 2 lletres majúscules de cada tipus de planejament, seguides, si escau, d' 1 lletra minúscula més per a indicar els subtipus. Es recomana evitar denominacions de significat reiteratiu com "urbanístic", "ordenació", "director", etc. perquè són genèriques i no aporten valor específic a la denominació. 


\begin{tabular}{|c|c|c|c|c|}
\hline \multicolumn{5}{|c|}{ Denominació de les figures de planejament } \\
\hline \multicolumn{2}{|l|}{ Àmbit } & Denominació & Codi & Subcodi \\
\hline \multirow{3}{*}{\multicolumn{2}{|c|}{$\begin{array}{l}\text { Supramunicipal: comarcal, } \\
\text { regional, etc. }\end{array}$}} & \multirow[t]{3}{*}{ Pla Director } & \multirow[t]{3}{*}{ PD } & PDg general \\
\hline & & & & PDp parcial \\
\hline & & & & PDs sectorial \\
\hline \multicolumn{2}{|c|}{ Municipal o plurimunicipal } & Pla d'Ordenació & $\mathrm{PO}$ & \\
\hline \multirow[t]{3}{*}{ Submunicipal } & $\begin{array}{l}\text { Sòl } \\
\text { urbanitzable }\end{array}$ & Pla Parcial & $\mathrm{PP}$ & PPd delimitador \\
\hline & $\begin{array}{l}\text { Sòl urbà no } \\
\text { consolidat }\end{array}$ & Pla Millora & PM & \\
\hline & $\begin{array}{l}\text { Sòl no } \\
\text { urbanitzable }\end{array}$ & Pla Especial & $\mathrm{PE}$ & \\
\hline \multicolumn{2}{|l|}{ Temàtic } & Pla Sectorial & PS & PSa (sectorial agrari) \\
\hline
\end{tabular}

Sistemes i subsistemes urbanístics: es proposa utilitzar com a codi la sigla majúscula de cada sistema o subsistema, més una segona lletra minúscula per indicar la categoria específica. Quan es tracta d'espais lliures d'edificació associats al sistema el segon dígit és el 0 . Quan es tracta de sistemes de nova creació proposats en sòl en transformació, se situa el codi entre parèntesi.

En aquells casos en que es contempli la coexistència de dos usos públics diferents en un mateix sòl classificat com a sistema, aquests es poden identificar amb les dues claus corresponents, separades per una barra inclinada $(\mathrm{N} / \mathrm{N})$ o per un guió $(\mathrm{N}-\mathrm{N})$. En el primer cas, la primera clau serà identificativa del sistema assignat al sòl i situat en un nivell topogràfic superior, i la segona clau, es correspon amb l'ús compatible situat en un nivell topogràfic inferior. En el segon cas es contempla la coincidència de funcions corresponents a dos sistemes diferents en un mateix terreny qualificat com a tal. 
Qualificació del sòl públic: sistemes i subsistemes

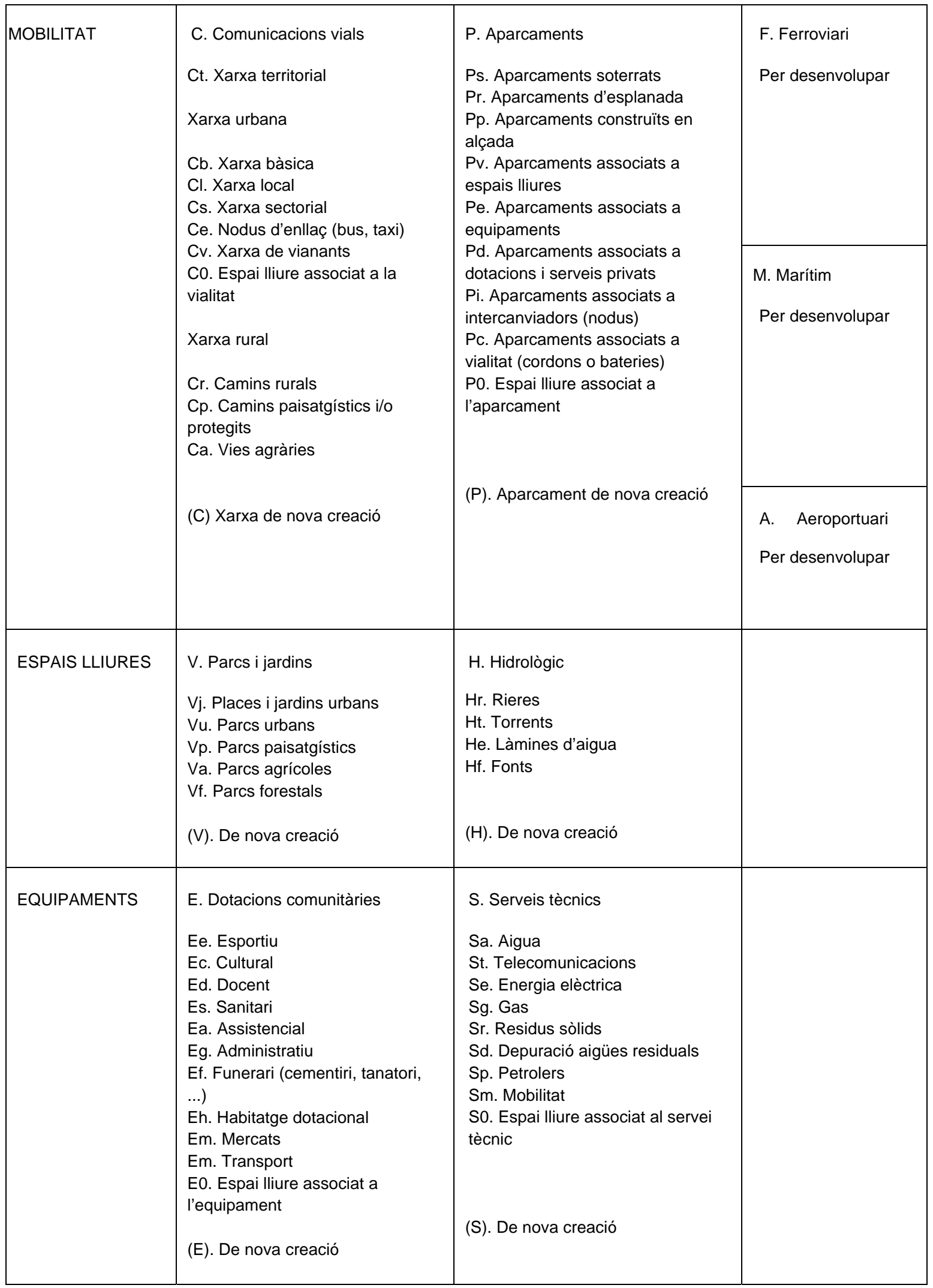




\section{Qualificació del sòl privat: zonificació}

Es proposa utilitzar com a codi un sistema on les dues primeres posicions són numèriques $\mathrm{i}$ a partir de la $3^{a}$ posició s'utilitzen lletres. Les dos primeres posicions indiquen la qualificació de la zona. La tercera posició, formada per una lletra minúscula, indica la subzona.

Si el primer número és un 0 indica que el sòl és no urbanitzable. Aquesta decisió pretén reforçar molt visualment el règim urbanístic d'aquest tipus de sòl.

Si el primer número no és un 0 indica que es tracta de sòl urbà. Aquesta decisió entronca amb la tradició d'identificar les zones urbanístiques amb números.

Si el codi està inclòs dins d'un parèntesi () la qualificació zonal correspon a sol urbanitzable o no consolidat. Aquesta decisió vol reforçar visualment el caràcter propositiu de la qualificació zonal.

Codificació al sòl urbà/urbanitzable:

La primera posició numèrica (1-9) indica la qualificació zonal, en general molt marcada per l'ús del sòl en primer lloc i en segon lloc per la tipologia edificatòria.

El dígit 1 correspon al teixit històric o tradicional de cada població.

Els dígits 2-5 corresponen als diferents teixits residencials més recents

(eixamples, blocs aïllats, ciutat jardí i alineacions).

El dígit 6 correspon a l'ús industrial

El dígit 7 correspon als equipaments privats (dotacions)

El dígit 8 correspon a sectors de transformació potencial cap a altres usos, encara per definir.

Resta disponible l'àmbit zonal 9 per a la casuística específica de cada municipi.

La segona posició numèrica, juntament amb la primera, acaba per definir la zona pròpiament dita. D'aquesta manera es disposa de fins 99 codis diferents per a identificar les qualificacions zonals d'un municipi, en principi suficients i ordenades segons una lògica.

Quan aquesta segona posició és 0 indica que es tracta d'un àmbit lliure d'edificació. Altre cop la presència del dígit 0 reforça el missatge de l'absència d'edificació.

La resta de dígits (1-9) corresponen a subtipus de la zona principal.

Es fa notar que per a cada àmbit zonal hi ha una sèrie de zones amb definicions que són comuns: p.e. "Sectors urbanístics desenvolupats" o "Conjunts Unitaris". Es tracta de zones que comparteixen alguna característica que les fa homogènies o singulars: be procedeixen d'un projecte arquitectònic unitari o be provenen d'un planejament anterior, etc.

La tercera posició és opcional i es proposa que sigui una lletra per tal d'indicar la subzona. 
Les subzones són en principi un conjunt obert, que presenta un gran potencial d'adaptació a la casuística de cada municipi i que es pot anar ampliant a mesura que s'incorporin nous sectors de planejament derivat o es regulin de forma més detallada els paràmetres d'una zona.

Codificació al sòl no urbanitzable:

Per a cada tipus de qualificació de sòl ( natural, forestal, agrícola, etc.) hi ha també una sèrie de subzones amb definicions comunes (p.e. l'ús residencial associat) i altres subzones ja més específiques per a cada tipus de sòl.

\begin{tabular}{|c|c|c|}
\hline ió & & \\
\hline SÒL NO URBANITZABLE & SÒL URBÀ & SÒL URBANITZABLE \\
\hline $\begin{array}{l}\text { 01. SÒL NATURAL } \\
\text { 01e. Interès ecològic } \\
\text { 01h. Habitatge natural associat (refugis) } \\
\text { 01p. Interès paisatgístic }\end{array}$ & $\begin{array}{l}\text { 1. RESIDENCIAL HISTÒRIC } \\
\text { 10. Àmbits lliures d'edificació } \\
\text { 11. Centre històric } \\
\text { 12. Històric dispers } \\
\text { 13. Fronts històrics de carrer } \\
\text { 14. Sectors urbanístics desenvolupats } \\
\text { 15. Conjunts unitaris }\end{array}$ & $\begin{array}{l}\text { (1) RESIDENCIAL HISTÒRIC } \\
\text { (10) } \\
(11) \\
(12) \\
(13) \\
(14) \\
(15)\end{array}$ \\
\hline $\begin{array}{l}\text { 02. SÒL FORESTAL } \\
\text { 02c. Forestal comú } \\
\text { 02e. Interès ecològic } \\
\text { 02h. Habitatge forestal associat } \\
\text { 02i. Forestal Intensiu (explotació) } \\
02 \mathrm{~m} \text {. Forestal d'emmagatzematge } \\
02 \mathrm{p} \text {. Interès paisatgístic } \\
02 \mathrm{r} \text {. Rehabilitació Forestal } \\
02 \mathrm{t} \text {. Tractament de residus } \\
02 z \text {. Altres }\end{array}$ & $\begin{array}{l}\text { 2. RESIDENCIAL COL·LECTIU } \\
\text { ALINEAT } \\
\text { 20. Àmbits lliures d'edificació } \\
\text { 21. Raval } \\
\text { 22. Eixample } \\
\text { 23. Intervencions al nucli antic } \\
\text { 24. Sectors urbanístics desenvolupats }\end{array}$ & $\begin{array}{lll}\text { (2) } & \text { RESIDENCIAL } & \text { COL.LECTIU } \\
\text { ALINEAT } & \\
& \\
(20) & \\
(21) & \\
(22) & \\
(23) & \\
(24) & & \\
& \end{array}$ \\
\hline $\begin{array}{l}\text { 03. AGRÍCOLA } \\
\text { 03c. Agrícola comú (extensiu) } \\
\text { 03e. Interès ecològic } \\
\text { 03h. Habitatge agrícola associat } \\
\text { 03i. Agrícola intensiu } \\
\text { 03m. Agrícola d'emmagatzematge } \\
\text { 03p. Interès paisatgístic } \\
\text { 03r. Rehabilitació agrícola } \\
\text { 03z. Altres }\end{array}$ & $\begin{array}{l}\text { 3. RESIDENCIAL COL·LECTIU } \\
\text { EDIFICACIÓ OBERTA } \\
\text { 30. Àmbits lliures d'edificació } \\
\text { 31. Blocs amb alineació independent } \\
\text { 32. Torres amb alineació independent } \\
\text { 33. Intervencions al nucli antic } \\
\text { 34. Sectors urbanístics desenvolupats } \\
\text { 35. Conjunts unitaris }\end{array}$ & $\begin{array}{ll}\text { (3) } & \text { RESIDENCIAL } \\
\text { EDIFICACIÓ OBERTA } \\
\\
(30) \\
(31) \\
(32) \\
(33) \\
(34) \\
(35) & \end{array}$ \\
\hline $\begin{array}{l}\text { 04. SÒL RAMADER } \\
\text { 04c. Ramader comú (extensiva) } \\
\text { 04e. Interès ecològic } \\
\text { 04h. Habitatge ramader associat } \\
\text { 04i. Ramaderia intensiva } \\
\text { 04m. Ramader d'emmagatzematge } \\
\text { 04p. Interès paisatgístic } \\
\text { 04r. Rehabilitació ramadera } \\
\text { 04t. Tractament de residus } \\
\text { 04z. Altres }\end{array}$ & $\begin{array}{l}\text { 4. UNITATS DE RESIDENCIA } \\
\text { ALINEADA } \\
\text { 40. Àmbits lliures d'edificació } \\
\text { 41. Alineacions de l'habitatge unitari } \\
\text { 42. Agrupacions alineades per parelles } \\
\text { 43. Intervencions al nucli antic } \\
\text { 44. Sectors urbanístics desenvolupats } \\
\text { 45. Conjunts unitaris }\end{array}$ & $\begin{array}{l}\text { UNITATS } \\
\text { ALINEADA } \\
(40) \\
(41) \\
(42) \\
(43) \\
(44) \\
(45)\end{array}$ \\
\hline
\end{tabular}




\begin{tabular}{|c|c|c|}
\hline $\begin{array}{l}\text { 05. SÒL RURAL } \\
\text { 05c. Rural comú } \\
\text { 05e. Interès ecològic } \\
\text { 05h. Habitatge rural associat } \\
\text { 05i. Rural Intensiu (explotació) } \\
\text { 05m.Rural d'emmagatzematge } \\
\text { 05p. Interès paisatgístic } \\
\text { 05r. Rehabilitació rural } \\
\text { 05t. Tractament de residus } \\
\text { 05z. Altres }\end{array}$ & 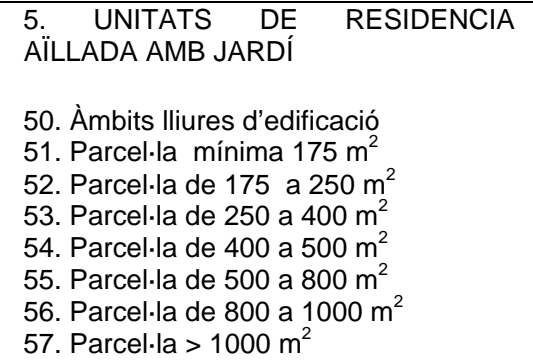 & $\begin{array}{lccc}(5) & \text { UNITATS DE } & \text { RESIDENCIA } \\
\text { AïLLADA AMB JARDÍ } & \\
& & \\
(50) & & \\
(51) & & \\
(52) & & \\
(53) & & \\
(54) & & \\
(55) & & \\
(56) & & & \\
(57) & & & \end{array}$ \\
\hline $\begin{array}{l}\text { 06. INDUSTRIAL } \\
\text { 06h. Habitatge industrial associat } \\
\text { 06i. Industrial intensiu } \\
\text { 06m. Industrial d'emmagatzematge } \\
\text { 06p. Interès paisatgístic } \\
\text { 06r. Rehabilitació industrial } \\
\text { 06t. Tractament de residus } \\
\text { 06x. Activitats extractives (manantials, } \\
\text { pedreres, mines) } \\
\text { 06z. Altres }\end{array}$ & $\begin{array}{l}\text { 6. INDÚSTRIA COL·LECTIVA } \\
\text { 60. Àmbits lliures d'edificació } \\
\text { 61. Industrial col-lectiu aïllat } \\
\text { 62. Col-lectiu agrupat en filera } \\
\text { 63. Col-lectiu agrupat en illa } \\
\text { 64. Sectors urbanístics desenvolupats } \\
\text { 65. Conjunts industrials unitaris } \\
\text { 66. Unitats industrials aïllades } \\
\text { 67. Unitats industrials agrupades } \\
\text { (mitgeres) en fileres } \\
\text { 68. Unitats industrials agrupades } \\
\text { (mitgeres) en illes } \\
\text { 69. Unitats industrials singulars }\end{array}$ & $\begin{array}{l}\text { (6) INDÚSTRIA COL·LECTIVA } \\
(60) \\
(61) \\
(62) \\
(63) \\
(64) \\
(65) \\
(66) \\
(67) \\
(68) \\
(69)\end{array}$ \\
\hline $\begin{array}{l}\text { 07. DOTACIONS PRIVADES } \\
\text { 07a. Comerç } \\
\text { 07c. Cultura } \\
\text { 07d. Docent } \\
\text { 07e. Esport } \\
\text { 07h. Habitatge associat } \\
\text { 07m. Emmagatzematge } \\
\text { 07p. Interès paisatgístic } \\
\text { 07q. Assistència a la mobilitat } \\
\text { 07s. Sanitat i assistència social } \\
\text { 07t. Turisme, restauració i lleure } \\
\text { 07r. Religiós i funerari } \\
\text { 07z. Altres }\end{array}$ & $\begin{array}{l}\text { 7. DOTACIONS PRIVADES } \\
\text { 70. Àmbits lliures d'edificació } \\
\text { 71. Comerç } \\
\text { 72. Hoteler, restauració i recreatiu } \\
\text { 73. Oficines i Serveis professionals } \\
\text { 74. Esport } \\
\text { 75. Docent } \\
\text { 76. Sanitat i assistència social } \\
\text { 77. Cultura } \\
\text { 78. Assistència a la mobilitat } \\
\text { 79. Religiós i funerari }\end{array}$ & $\begin{array}{l}\text { (7) DOTACIONS PRIVADES } \\
(70) \\
(71) \\
(72) \\
(73) \\
(74) \\
(75) \\
(76) \\
(77) \\
(78) \\
(79)\end{array}$ \\
\hline 08. DISPONIBLE & $\begin{array}{l}8 . \quad \text { SECTORS } \\
\text { DESENVOLUPAMENT } \\
\text { POTENCIAL }\end{array}$ & (8) DISPONIBLE \\
\hline 09. DISPONIBLE & 9. DISPONIBLE & (9) DISPONIBLE \\
\hline
\end{tabular}

Resten disponibles els codis 08 i 09 per a donar resposta a les especificitats pròpies de cada municipi.

A continuació es mostren exemples gràfics d'aplicació de la codificació. 


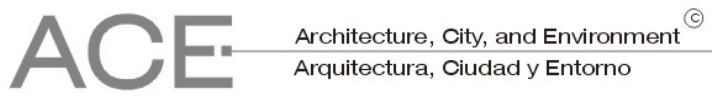

Exemple de l'aplicació de la codificació simplificada proposada a un sector de sòl urbà no consolidat.

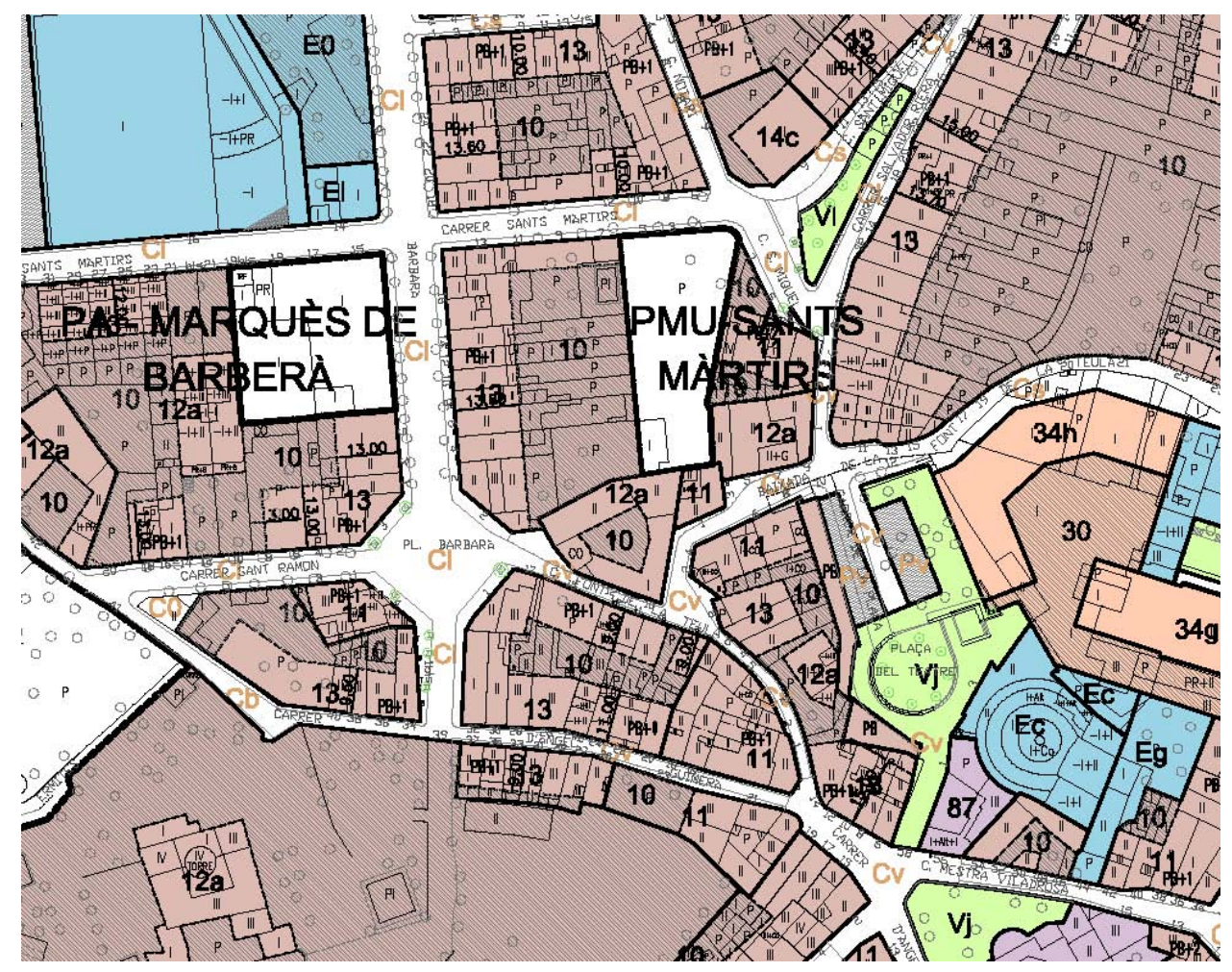

Exemple de l'aplicació de la codificació simplificada proposada a un sector de sòl urbà consolidat.

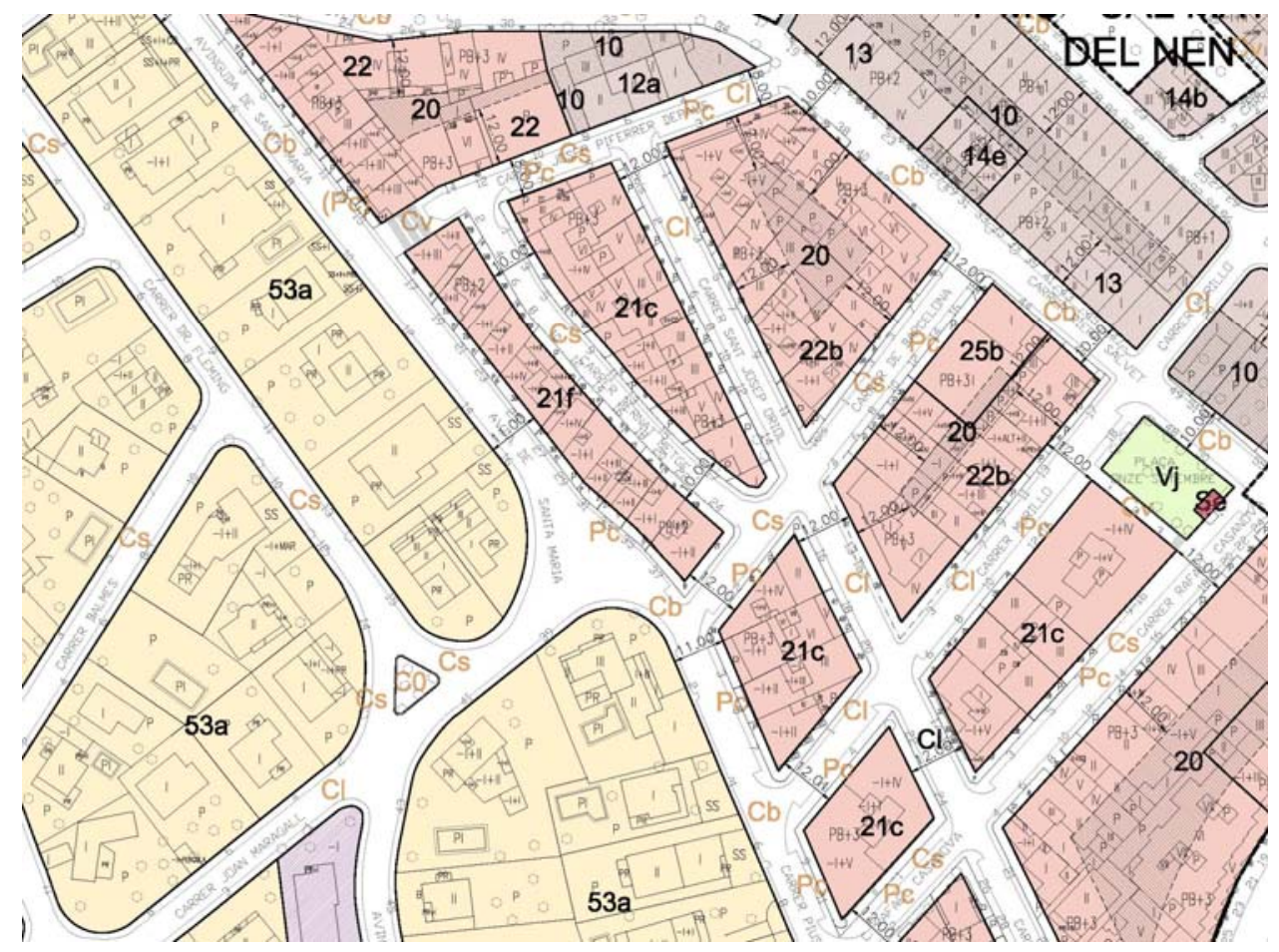




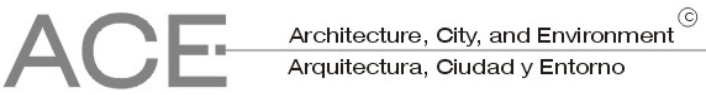

Exemple de l'aplicació de la codificació simplificada proposada a un sector de sòl urbanitzable

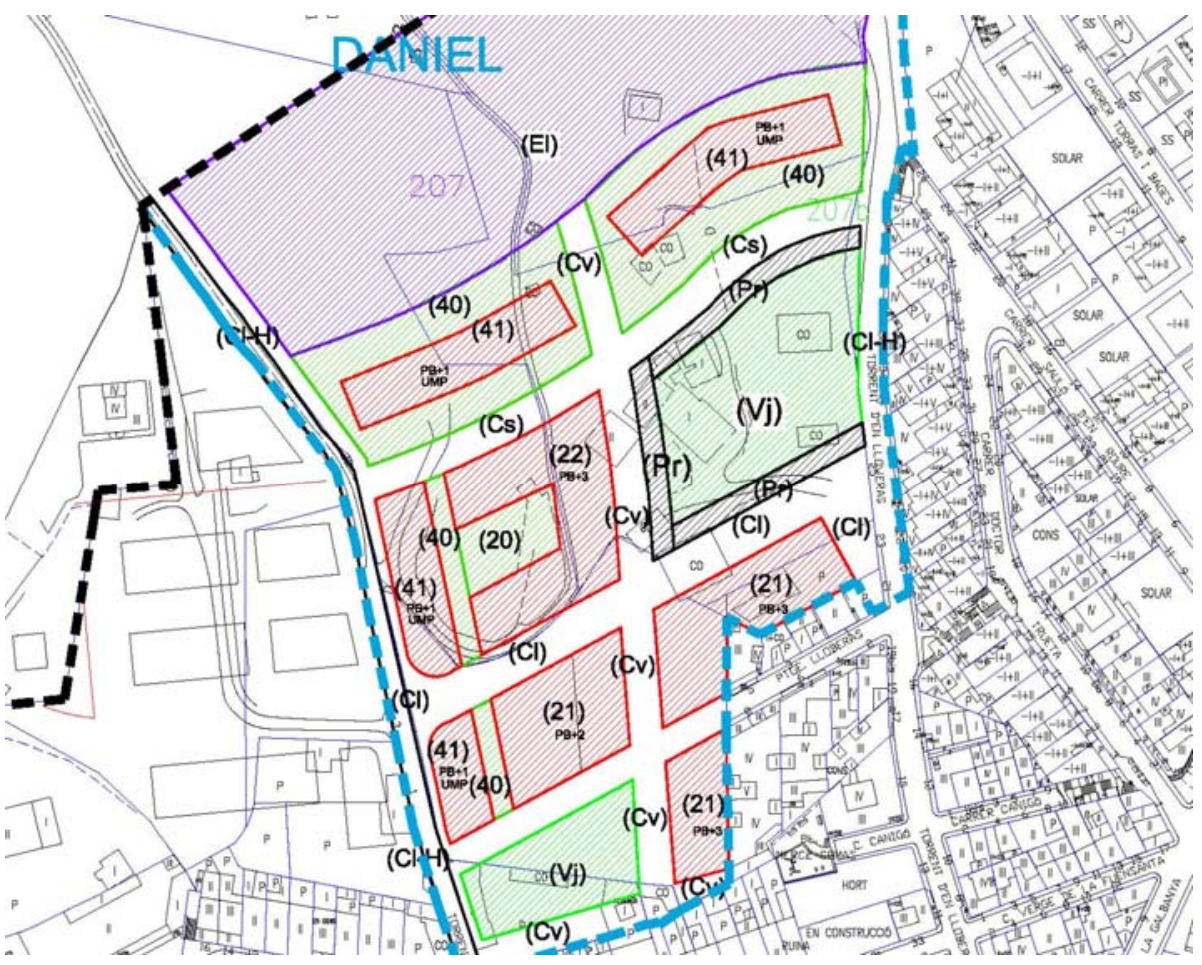

Exemple de l'aplicació de la codificació simplificada proposada

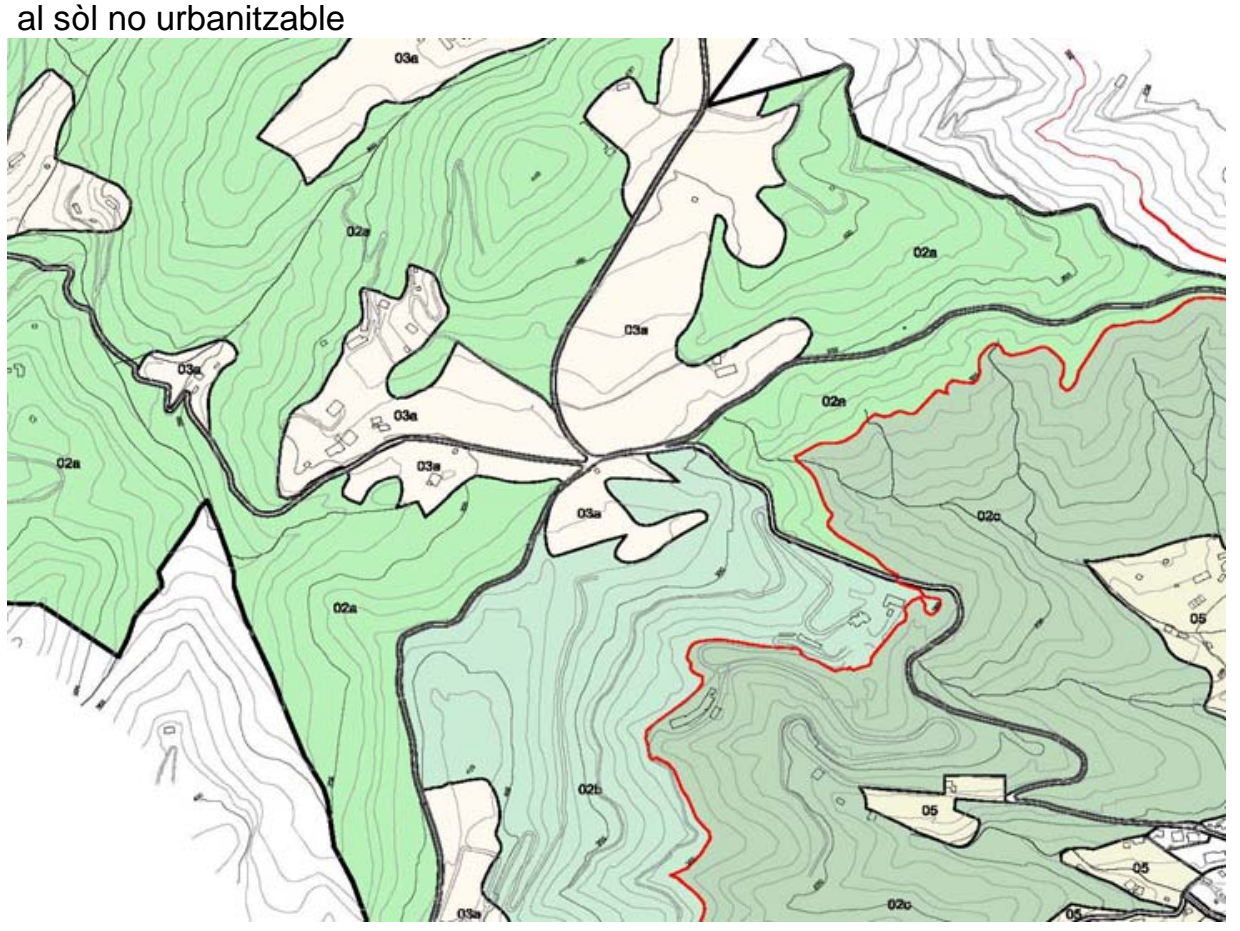




\section{CONCLUSIONS}

L'experiència d'aplicació d'aquesta codificació simplificada ha estat satisfactòria tan des del punt de vista de l'equip redactor com des del punt de vista dels professionals i ciutadans que han presentat al-legacions en les diverses etapes d'aprovació. Les tasques s'han simplificat, el sistema s'ha demostrat flexible i els consultors s'han adaptat ràpidament als canvis que es proposen. Hom espera que aquesta aportació sigui una baula més en el procés de millora contínua dels documents que donen suport material al planejament urbanístic.

\section{BIBLIOGRAFIA}

\section{Revistes}

\begin{tabular}{ll}
\hline Autorla: & Clara Galiano, cap del Servei de Documentació i Estudis de la Direcció General \\
Títol: & d'Urbanisme de la Generalitat de Catalunya \\
Referència: & "Codificació de informació de Planejament" \\
Editorial: & Revista INDE (Informació i Debat), juny de 2005, pàgina 41 \\
Lloc de publicació: & Publicació de la Demarcació de Barcelona del Col·legi d'Arquitectes de Catalunya \\
\hline
\end{tabular}

En aquest article, Clara Galiano presenta un estudi de codificació de la informació de planejament i destaca que l'aplicació d'aquesta codificació gràfica és imprescindible per assolir un millor aprofitament i explotació de les possibilitats dels sistemes d'informació geogràfica.

\section{LEGISLACIÓ}

\section{Lleis}

- Llei 2/2002, de 14 de març, d'urbanisme (DOGC núm. 3600, de 21 de març de 2002)

- Decret 287/2003, de 4 de novembre, pel qual s'aprova el Reglament parcial de la Llei 2/2002, de 14 de març, d'urbanisme. DOGC núm. 4022 - 02/12/2003 (Pàg. 23450) 
- Llei 10/2004, de 24 de desembre, de modificació de la Llei 2/2002, del 14 de març, d'urbanisme, per al foment de l'habitatge assequible, de la sostenibilitat territorial $i$ de l'autonomia local.

- Decret 1/2005, de 26 de juliol, pel qual s'aprova el Text refós de la llei d'urbanisme

- Decret 305/2006, de18 de juliol, pel qual s'aprova el Reglament de la llei d'urbanisme

La diferent legislació consultada fa referència als continguts dels documents de planejament, però sense fer cap aportació per a la codificació d'aquests.

Per a la proposta simplificada s'ha tingut en compte les definicions de les classificacions del sòl i dels àmbits de planejament incloses en la legislació d'àmbit català.

\section{Normes}

\begin{tabular}{|l|l|l|l|}
\hline Norma & Àmbit territorial & Descripció & Organisme responsable \\
\hline CEN / TC 287 & Europeu & $\begin{array}{l}\text { Normalització de la } \\
\text { informació geogràfica }\end{array}$ & $\begin{array}{l}\text { Centre Europeu de } \\
\text { Normalització }\end{array}$ \\
\hline ISO / TC 211 & Mundial & $\begin{array}{l}\text { Normalització de la } \\
\text { informació geogràfica }\end{array}$ & $\begin{array}{l}\text { Organització } \\
\text { Internacional per a la } \\
\text { Estandardització }\end{array}$ \\
\hline
\end{tabular}

Aquestes normes es centren bàsicament en la informació gràfica de base, planimetria i topografia, i la seva georeferenciació i facilitat d'intercanvi. 